\title{
Mothers with breast cancer: A mixed-method systematic review on the impact on the
}

\section{parent-child relationship}

\section{Rita Tavares}

Faculty of Psychology and Education Sciences, University of Porto, Portugal Tânia Brandão

Faculty of Psychology and Education Sciences, University of Porto, Portugal

Center for Psychology at University of Porto

Paula Mena Matos*

Faculty of Psychology and Education Sciences, University of Porto, Portugal

Center for Psychology at University of Porto

* Corresponding author contact information:

Paula Mena Matos

Rua Alfredo Allen

4200-135 Porto

Portugal

Telephone number +351226079700

Fax +351226079725

Email:pmmatos@fpce.up.pt

Please Note: This is the author's version of the manuscript accepted for publication in Psycho-Oncology. Changes resulting from the publishing process, namely editorial editing, corrections, final formatting for publication, and other modifications resulting from quality control mechanisms may have been subsequently added.

A definitive version was subsequently published as: Tavares, R., Brandão, T., \& Matos, P. M. (2018). Mothers with breast cancer: A mixed-method systematic review on the impact on the parent-child relationship. Psycho-Oncology, 27, 367-375. Doi: 10.1002/pon.4451 


\begin{abstract}
Objective: To systematically review and integrate the findings from quantitative and qualitative studies on parenting and parent-child relationships in families where mothers had Breast Cancer (BC).

Methods: Ten different databases were searched from inception to January 2016. All authors assessed these data independently. Full-text, peer-reviewed articles exploring parenting and/or mother-child relationships in families where the mother had BC, regardless of cancer stage, were considered for inclusion. PRISMA guidelines were followed.

Results: From 116 studies, 23 were deemed eligible for inclusion. Five of them were quantitative, 15 were qualitative, and one study used a mixed-method approach. Most studies analysed the mother's perceptions about the experience of having $\mathrm{BC}$ in parenting and in the parent-child relationship. The majority of studies explored experiences and perspectives on the parent-child relationship in mothers with minor children, although a minority of studies included adult children. Additionally, a few studies (17\%) addressed perceptions and experiences of women with advanced stage cancer. Three main themes were found: priorities and concerns of patients; decision-making processes about sharing the diagnosis with their children; and mother-child relationship and parenting after mother's diagnosis.

Conclusions: Findings indicated that the diagnosis of $\mathrm{BC}$ is accompanied by an array of challenges that affect parental roles and parenting. Further studies are needed in order to explore these issues more sensitively. For now, however, the evidence suggests that the families of women with $\mathrm{BC}$, and particularly the women themselves, may benefit from informal and formal support aimed at helping them cope effectively with this challenging life event.
\end{abstract}


Keywords: cancer, oncology, breast cancer in women, mother-child relationship, parenting, systematic review; psycho-oncology.

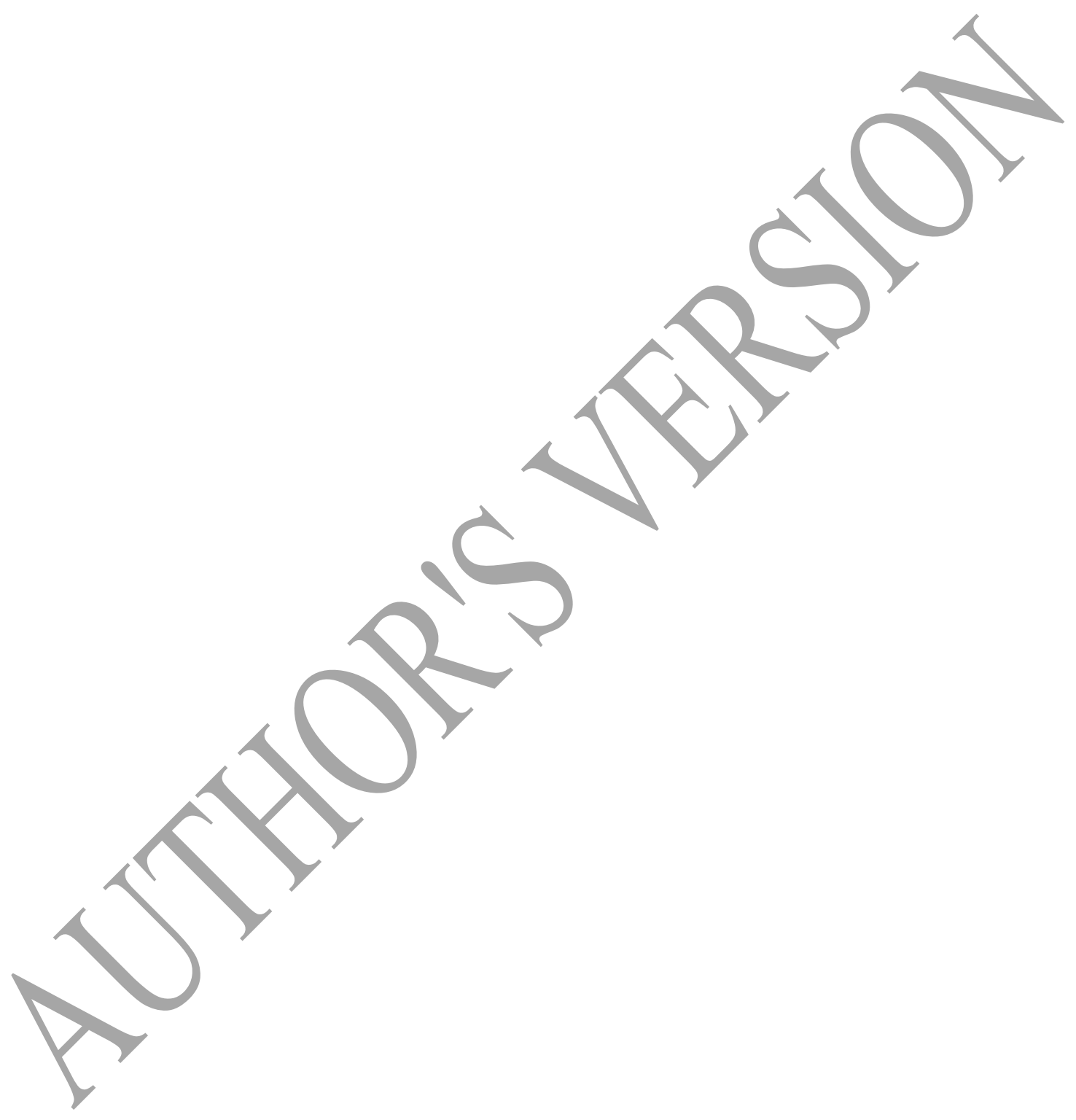




\section{Introduction}

Breast Cancer (BC) is the most common type of cancer in women worldwide ${ }^{1-3}$ and leading cause of death for women in Europe ${ }^{3}$. It is estimated that 255,180 women will be diagnosed with BC in United States of America, in $2017^{4}$, and that $12 \%$ of women in the United States of America will develop BC at some time during their lives ${ }^{1}$. Also, the rate of women diagnosed with $\mathrm{BC}$ before the age of 40 years has increased, corresponding to $6.6 \%$ of the total number of cases of BC diagnosis ${ }^{5}$. Still, in Europe and Northern America, the mortality rate has been decreasing since the 1990's.

When a woman is confronted with a BC diagnosis, she often experiences an immediate threat to her survival ${ }^{6}$, along with the emergence of doubts and fears about future implications of the cancer in her daily life and relationships ${ }^{7-9}$. A BC diagnosis not only affects the patient but also instigates a crisis in the family system by triggering changes in family dynamics, roles, rules, and routines ${ }^{9-11}$. Among diagnosed mothers under the age of 40, one particular challenge is that their children are usually minor and thus more dependent on them ${ }^{12,13}$. Being a mother is a primary role even when women are ill $^{12,14}$. As women facing a $\mathrm{BC}$ diagnosis and related-treatments must concurrently manage their roles as mothers, these circumstances can adversely affect both their psychological well-being ${ }^{12,13}$ and sense of competent mothering 9

Parenting can be affected by $\mathrm{BC}$ in different ways compared to other oncological diseases, since BC may have a big impact on patients' body image ${ }^{15-17}$. After breast surgery, some mothers tend to avoid physical contact with their children because they did not want their children to notice their body transformations ${ }^{18}$. Additionally, some mothers made axillary dissection and their physicians advised against physical efforts, such as picking up and holding their children, in order to avoid lymphedema ${ }^{18,19}$. These two situations are specific characteristic of BC and can cause negative feelings (e.g., guilt) and thoughts (e.g., 
sometimes they consider themselves bad mothers) ${ }^{18,20-22}$. Additionally, the gender of the sick parent affected children's adjustment to the cancer of their parent ${ }^{23}$. So, it is important to understand the specificities of BC in mothers and how these affect parenting and parent-child relationship. However, there are also common points in parenting when one parent has cancer, regardless of the type of cancer ${ }^{9,24,25}$. For example, in some occasions due to the side effects of treatments, sick parents may have difficulties in responding to children's needs ${ }^{9,26}$. Parents are naturally protective of their children and for this reason try to maintain closeness and daily routines to minimize disruptions in the family system ${ }^{9}$. Whether or not parents should share and talk openly with their children about their illness is commonly a difficult decision faced by families in which a parent has been diagnosed with cancer. While some parents decide to openly discuss the disease with their children ${ }^{11,27}$, others try to avoid this topic ${ }^{28-30}$. Although the latter decision is often made to protect children's well-being, some studies have shown that, in general, children do not experience serious psychosocial difficulties after knowing that their mothers have cancer ${ }^{31}$. However, other studies showed different results, demonstrating that the stress and distress levels are higher in children of parents with cancer ${ }^{24,32,33}$. The children's psychosocial functioning has been associated with family functioning variables like cohesion, communication, and affective involvement ${ }^{30-33}$. For example, Edwards and colleagues ${ }^{33}$ found a relationship between little family cohesion and poor family functioning with the emergence of external and emotional problems in adolescents whose mother has BC. The communication between family members and the experience of appropriate affect in the family context are also important in order to avoid internalising and externalising problems in children of mothers with cancer ${ }^{33}$. In the general context of cancer, preliminary evidence seems to suggest that the parent-child relationship is likely to improve ${ }^{9}$. However, this issue has been largely underexplored in the context of BC. 
The first studies on women with BC focused essentially on patient's well-being, and on how women reacted and coped with this disease. Since 1990, however, attention has been paid to the impact of $\mathrm{BC}$ on motherhood and on the mother-child relationship ${ }^{9}$. The present study provides a mixed-method systematic review of the quantitative and qualitative studies regarding the impact of the mother's diagnosis of $\mathrm{BC}$ on the parent-child relationship and on parenting. Our intent is to assist researchers in planning future studies by identifying dimensions and processes that deserve more specific scientific attention. It is also hoped that this review will provide valuable information to healthcare professionals and especially to psycho-oncologists, for improving the care and support they offer to women and families facing BC.

\section{Method}

This systematic review followed the guidelines of Preferred Reporting Items for Systematic Reviews and Meta-Analyses (PRISMA) ${ }^{34}$. Studies were included if they analysed the parent-child relationship and parenting in families where mothers had BC, regardless of cancer stage and children' age. Exclusion criteria were: (a) studies including only healthy participants; (b) studies focusing only on BC in men; (c) studies that did not analyse either the parent-child relationship or parenting in families wherein the mother had BC; (d) studies including other types of cancer or diseases; (e) and, finally, literature reviews, books, unpublished articles and doctoral theses, commentaries, abstracts of conferences and congresses.

Database searches were conducted from inception to January 2016 in Academic Search Complete, CINAHL Plus with Full Text, ERIC, MedicLatina, MEDLINE with Full Text, PsycARTICLES, PsycCRITIQUES, Psychology and Behavioral Sciences Collection, and PsycINFO. This search was supplemented by additional hand searching in Google. 
Search terms used were: parenthood* OR mother-child* relationship OR father-child* relationship OR parenting* OR parent-child relationship OR motherhood* AND breast cancer in women. After removing duplicates, titles and abstracts were assessed for eligibility independently by three independent raters. Disagreements between raters were discussed and resolved by consensus.

\section{Results}

\section{Description of studies}

A total of 178 articles were identified. After duplicates were removed, 116 studies remained and the abstracts were examined. From these, 92 were excluded for the following reasons: 10 only included healthy participants; 64 did not analyse either the mother-child relationship or parenting; one included other types of cancer or diseases; and 17 were literature reviews or abstracts of conferences or congresses (see Figure 1). A total of 24 studies were retrieved for full text screening. From these, one was excluded because it incorporated other types of cancers or diseases ${ }^{9}$. Thus, a total of 23 studies exploring the mother-child relationship and parenting in families where mother had BC were retained. A detailed description of the included studies is presented in the supplemental material.

Most of the reviewed studies explored the experiences of mothers with minor children $^{19-21,35-42}$, although some concurrently included mothers with minor and adult children 6,22,43-46 However, six studies did not identify children's age (three did not report information about this issue ${ }^{12,47,48}$, one noted only that mothers had dependent children $^{49}$, and two indicated that mothers had both dependent and adult children $\left.{ }^{50,51}\right)$. Overall, only two studies gathered and included children's perspectives as well as mothers' perspectives ${ }^{40,44}$. The remaining studies limited their analyses to the mothers' perspectives about how their BC affected their families and themselves ${ }^{6,12,19-22,35-39,41-43,45-51}$. Regarding the cancer stage, six 
studies included women with early stage BC (I-III) ${ }^{19,35-37,44,47}$ and four included women with advanced stage $\mathrm{BC}^{12,22,40,41}$. Additionally, one study analysed women with primary $\mathrm{BC}^{43}$, and three studies included women with non-recurrent $\mathrm{BC}^{6,20,48}$. In nine studies, no information regarding cancer type was provided ${ }^{21,38,39,42,45,46,49-51}$. The majority of studies employed qualitative designs (17), while five were quantitative and one used a mixed-method design. Most studies were conducted in Europe $(n=9)$, followed by America $(n=5)$, Australia $(n=$ 5), and Asia $(n=4)$. The average of sample sizes among the qualitative studies was 25 , ranging from six to 169 participants. Among the quantitative studies (including the one using a mixed-method approach), the average of sample sizes was 189, ranging from 32 to 313 participants. With regards to data analyses, the majority of qualitative studies used content analysis, and the majority of quantitative studies used regression analysis.

\section{Themes from the literature}

Thematic analysis ${ }^{52}$ was used to synthesize quantitative and qualitative findings. After analysing all findings of the 23 studies, the first author identified 43 dimensions regarding the experience of being a mother with $\mathrm{BC}$. The dimensions with similar meanings were subsequently grouped into 15 dimensions. All the authors discussed the findings obtained by thematic analysis, and agreed with the reorganization on 15 dimensions. These dimensions were then categorized according to three main themes: (a) priorities and concerns of patients;

(b) decision-making process about sharing the diagnosis with children; and (c) mother-child relationship and parenting after mother's diagnosis (see Table 1). It is important to note that these three themes were not reported simultaneously in all studies (see Table 2).

Theme 1: Priorities and concerns of patients 
After receiving their $\mathrm{BC}$ diagnosis, mothers appeared to establish their priorities in terms of social roles ${ }^{49}$. Studies showed that, after their diagnosis, women reaffirmed and intensified their priorities regarding their families, and especially to meeting their children's needs ${ }^{6,19,43,45,49}$. Even when these women recognized that they should focus on their treatment-related requirements, they reported difficulties prioritizing their $\mathrm{BC}$ treatment over their children's needs ${ }^{19}$. On the contrary, patients tend to prioritize health and well-being over the paid work ${ }^{49}$. Furthermore, when women were required to deal with their cancer-related adjustments (e.g., feelings of exhaustion after treatments), they reported diminished parenting efficacy and heightened negative effects and thoughts, such as sadness, guilt, and concerns about being a bad mother ${ }^{20-22}$. Their concerns regarding children were seemingly associated with the demands of their maternal role and with social conceptions about parenting that emphasized the greater importance of their children's needs ${ }^{19,21,49}$, regardless of the physical and emotional implications of their own $\mathrm{BC}^{21}$. Indeed, this appraisal also likely influenced their decisions about when to start the treatments and what type of treatments to pursue ${ }^{49}$. For example, some mothers delayed the beginning of their treatments because they did not want to disturb their families during special times, like Christmas ${ }^{49}$. Other concerns included how and what to tell to their children about their $\mathrm{BC}$ diagnosis 22 ; how their children might react to the possibility of losing their mother ${ }^{6,12}$; their children's futures ${ }^{6,12,20,51}$; and how the father will take care of their children if patient dies ${ }^{6,12}$.

Regarding how and what to tell to their children about the diagnosis, one of their main concerns was related to the children's possible reactions to the diagnosis and to the prospect of losing their mothers ${ }^{20,45}$. In some cases, these concerns stimulated the mother's development of action plans for ensuring that children would be cared for after her death $^{6,20,38}$. Another common concern was the possibility of having an hereditary cancer that would increase their children's risk of having cancer ${ }^{47}$. 
These informational and relational uncertainties led some women, especially in the first year after breast surgery ${ }^{50}$, to approach their health professionals for assistance in determining what and how to tell their children about their BC diagnosis ${ }^{36,41}$, how to talk to them about death $22,37,41$ and about the concerns they have $\mathrm{e}^{41,50}$. Additionally, some mothers requested that psychosocial support services be made available to their children in order to make the hospital a more familiar setting to them ${ }^{36}$. However, few mothers reported receiving this support ${ }^{41,50}$, and in some cases, despite the support of counsellors, these women remained dissatisfied because they considered that these professionals were unaware of the specific issues faced by women with advanced $\mathrm{BC}^{41}$. Moreover, some women reported that their health professionals avoided talking about this topic ${ }^{41}$. Taken together, these women's experiences with health professionals seemed to deepen their feelings of loneliness and anxiety about how to manage their conversations with their children ${ }^{41}$. As a result, they sought advice and support from their children' teachers for how they should act with their children in the future ${ }^{46}$.

Theme 2: Decision-making process about sharing the diagnosis with children

The mother's decisions about whether or not to share the diagnosis with her children was apparently influenced by the perceived effects that this disclosure would have on both their children and themselves ${ }^{6,35,36,41,42}$. Both possible decisions have as main goal to protect their children's well-being ${ }^{6}$. Cultural factors also seemed to influence this decisional process. For instance, in Saudi Arabia, where the religion has a fundamental role in people's lives, some mothers explained to their children that $\mathrm{BC}$ was a proof of God's love in order to strengthen their children's religious faith ${ }^{35}$. However, the results from this qualitative study should be interpreted with caution, as its small sample may not have been representative of 
the larger Arab population. Overall, the findings suggest that this decision-making process requires considerable time and sustained personal reflection ${ }^{42}$.

The reviewed studies identified several reasons and motivations that supported women's decisions to share their diagnosis with their children. These included the belief that their children had the right to know; the mothers' desire to maintain feelings of trust and safety with regards to their children $36,39,41,43,46$ and to minimize their children's concerns and possible misperceptions about the deterioration of her physical appearance $19,35,36,42$; and the mothers' intentions to promote effective coping strategies in their children ${ }^{35,42}$. Additionally, some studies showed that mothers who shared their BC diagnosis subsequently experienced less stress, greater relief ${ }^{42}$, and perceived higher levels of social support from their children ${ }^{19,42}$.

In comparison, the mothers who chose not to share the $\mathrm{BC}$ diagnosis with their children appeared to do so in order to avoid uncomfortable questions ${ }^{36,42}$, an intensification of emotional distress (e.g., anxiety symptoms) ${ }^{35,36,42}$ and physical discharge in their children ${ }^{42}$, and also to preserve special moments in family (e.g., vacations). Other mothers based their decision of not to disclose the nature of their illness on the assumption that their children would be unable to understand the BC diagnosis ${ }^{36}$, particularly if they were very young ${ }^{19,36,49}$.

Relatedly, when mothers decided to talk about their BC with their children, they used language that was appropriate to the children's age and developmental level ${ }^{46}$, and they provided details that were sensitive to the children's needs ${ }^{43}$. In the latter study, older children (over 12 years) received more information about the mother's BC than did their younger counterparts ${ }^{37}$. Another study, however, indicated that mother's provision of information was not related to the child's age, but rather based on her personal beliefs ${ }^{39}$ and influenced by a wide range of factors such as the quality of the mother-child relationship, patterns of family functioning in previous stressful events, and the children's personality ${ }^{43}$ 
and current knowledge regarding $\mathrm{BC}^{45}$. Children lacking this knowledge made it difficult for mothers to share information with them in language that was appropriate for their age ${ }^{45}$.

In general, mothers only talk with their children when they have a definitive or factual information to share regarding their diagnosis and treatment plans ${ }^{37,43}$. Additionally, patients need to decide what they will tell to their children ${ }^{39,42}$. In some cases, rather than telling to their children that they had cancer, mothers only said that they were ill ${ }^{42,43,46}$. Usually, patients talk with their children about treatments and their related-effects (e.g., hospitalization, exhaustion/fatigue, and hair loss), because these effects result in clearly observable consequences ${ }^{42}$ that will likely require unexpected changes in children's lives for which they must be prepared ${ }^{39}$. Additionally, patients explain to their children the treatment procedures and why they need to make these treatments ${ }^{39,4}$

In some families, these mother-child conversations could be characterized as "unidirectional" in that mothers did not check with their children to ascertain whether or not they understood what was being said ${ }^{39}$. Moreover, even when mothers were open to discussing their children's doubts and questions regarding BC, they rarely explored their children's feelings, and instead focused on their children's thoughts about the provided clinical information ${ }^{39}$.

Theme 3: Mother-child relationship and parenting after mother's diagnosis

The studies about parenting after mother's diagnosis focus on many dimensions, such as beliefs about parental abilities after BC, division of parental tasks, parenting strategies in order to protect children, and implications of being a mother in the process of adaptation to the disease.

Providing care to children is the main parental task but that is made specially difficult given the physical and psychological problems related to $\mathrm{BC}$ (e.g., lymphedema or 
depression $)^{19}$. Mothers with BC often perceive their parenting abilities as diminishing over time, and their sense of failure in meeting their caretaking responsibilities towards their children as increasing ${ }^{21,44}$. Predictably, these trends concurrently augment mothers' feelings of frustration ${ }^{47}$ and reduce their satisfaction with their parental role ${ }^{44}$. In these situations, mothers use support from others (e.g., family, friends, and social support) in order to promote a normal family functioning ${ }^{20,22}$. Sometimes, it is the patient's support network that spontaneously tries to decrease the parental concerns and responsibilities of these mothers 49 by assuming some of the parental tasks ${ }^{49}$.

In other studies, mothers tended to use a variety of strategies for coping, with their BC diagnosis while simultaneously fulfilling their parental responsibilities ${ }^{6}$ to minimize any negative impacts of their illness on their children's functioning ${ }^{39,43}$. Findings from these studies can be organized into eight types of strategies: (a) using physical and emotional support available in order to save energy and strength to cope with $\mathrm{BC}^{6}$; (b) focussing on positive experiences triggered by the disease ${ }^{6,39}$; (c) maintaining routines ${ }^{6,20-22,39,41,43,46,49}$; (d) being involved in distracting activities in order to acquire energy, and to decrease negative thoughts about the disease ${ }^{48}$; (e) increasing their availability to their children, (f) including children in the family solving problems ${ }^{39,43}$; (g) promoting leisure moments in family; and (h) encouraging open communication about the disease $\mathrm{e}^{39,41,43}$. For example, mothers try to focus on the positive effects of $\mathrm{BC}$ by spending more time with children ${ }^{6,39}$, and playing a more active role in their education ${ }^{39}$.

As previously mentioned, 10 of the 23 articles presented in this systematic review found that mothers try to maintain their children's routines in order to protect them ${ }^{6,20-}$ $22,39,41,43,45,46,49$. This strategy has the benefits of minimizing disruptions in their children's lives $^{6,21}$ while promoting their feelings of security, protection, and comfort ${ }^{21,41}$. At the same time, this strategy can reduce the mother's concerns regarding the impact of her BC on her 
children ${ }^{6}$ and promote sense of normality within the family ${ }^{20,21}$. Mothers try to show their children that they are living a normative life event ${ }^{21}$. However, they can have some difficulties in dealing with family responsibilities while facing $\mathrm{BC}^{21}$. Thus, when they are less available to their children due to treatments and side effects, some mothers experience feelings of loss, pain ${ }^{47}$, sadness and guilt, and sometimes they consider themselves bad mothers ${ }^{20-22}$.

While some studies showed that mothers talk openly about $\mathrm{BC}^{39,41,43}$, others showed that sometimes mothers tend to suppress their emotions $s^{6,38,43,45}$ in order not to expose their children to some side effects of the treatments (e.g., hair loss) ${ }^{43}$. Occasionally, this happens because they are trying to maintain normality or because children do not want to know or see these side-effects ${ }^{43}$. However, because this strategy may require that mothers use emotional suppression to decrease the impact of $\mathrm{BC}$ in their children, it may also have negative consequences for their emotional well-being ${ }^{37,38}$. The use of emotional suppression usually increases anxiety levels and depressive symptoms, since mothers need to make more deliberate efforts to avoid talking about their cancer and related-issues in the presence of their childen $^{37,38}$.

Regarding parental rules, only one study ${ }^{40}$ demonstrated that these rules changed when the mother had $\mathrm{BC}$, with some mothers acknowledging that they became more tolerant of their children's behaviors ${ }^{40}$. In addition to these changes in parental rules, mothers' goals for their children also appeared to change. For example, mothers reported that they no longer focused exclusively on providing the best education and opportunities for their children, but instead focused on providing autonomy ${ }^{19}$, security, and protection ${ }^{45}$.

Regarding the mother's availability to her children, results are not consistent. While some studies showed that mothers felt their availability for their children decreased during active periods of $\mathrm{BC}$ treatments ${ }^{20,21}$, other studies showed that, after $\mathrm{BC}$ diagnosis, mothers 
spent more time with their children and played a more active role in their development, at least temporarily ${ }^{39}$.

When women received a $\mathrm{BC}$ diagnosis, some concerns emerged regarding parental abilities of the husband to educate their children alone ${ }^{6,12}$. Despite these concerns, in some cases, the father became more active and involved in children's education during $\mathrm{BC}$ treatments ${ }^{47}$. This change triggers an improvement in the father-child relationship, and some mothers become satisfied with this division of parental responsibilities ${ }^{47}$. Additionally, in some families, the children's role within the family also changed, as children tend to take care of their mothers after BC diagnosis ${ }^{47}$. When children know that their mother is ill, they start to provide more emotional and instrumental support and, consequently, the mother-child relationship tends to improve ${ }^{19,42}$. Also, sometimes children tend to use the support from other significant figures when they have some problem ${ }^{49}$. This way they try not to disturb their mother ${ }^{49}$. Mothers acknowledged that this shift in the child's seeking attitudes helped them during this period ${ }^{49}$.

Finally, studies showed that being a mother seems to function as a protective factor for women with BC, as their children's needs for care provide them with an important motivation for coping adaptively with their life circumstances ${ }^{6,45,48}$. This happens because mothers feel that children need their care. In particular, these mothers avoided indulging in negative thoughts of giving up, thereby sustaining their positive motivation to cope with the disease ${ }^{6,4}$

\section{Discussion}

This systematic review sought to analyse and systematize the available knowledge of the impacts of a mother's BC diagnosis on parenting and the parent-child relationship. To the best of our knowledge there are no previous systematic reviews that have focused on this 
particular topic. Few studies were found and most of them were qualitative in nature, thus underscoring the importance of identifying potentially fruitful directions for future research in this domain.

Generally, the findings indicated that parenting is a primary role for mothers with $\mathrm{BC}$, since in many studies these women prioritized their children's well-being and their active roles as mothers over the treatment-related requirements of their disease. These consistent findings affirm the importance of exploring parenting and mother-child relationship issues within this context. The main findings from this review were organized around the following three major themes, namely: (a) priorities and concerns of patients; (b) decision-making process about sharing the diagnosis with children; and (c) mother-child relationship and parenting after mother's diagnosis. Most studies explored the decision about sharing or withholding disclosure of the mother's diagnosis with children and all of these studies focused on factors associated with this decision ${ }^{6,19,35-37,39,41-43,45,46,49}$, as well as on explanations given to children $6,35,37,39,41-43,46$. It is clear that the decision about if, when, and how to tell to their children about BC diagnosis is a difficult task that can amplify the distress that accompanies $\mathrm{BC}$ diagnosis and treatment.

Studies on mother-child interaction in these affected families focused attention on the behaviours adopted by parents to prevent disruptions in their children's lives ${ }^{6,20-22,37-}$ 39,41,43,45,46,49. Again, maintaining children's well-being and their normal routines emerged as important priorities for parents coping with BC. Some mothers used open communication about BC as a parental strategy to protect their children ${ }^{39,41,43}$, and this strategy has been shown effective in promoting children's adjustment to the parents' diagnosis ${ }^{11,27}$. Moreover, when families avoided talking about parent's cancer, children's well-being (and especially that of adolescents) was likely to be adversely affected ${ }^{28-30}$. The importance of open communication was also present when women expressed their needs for professional 
guidance in talking about their concerns with their children $22,36,37,41,50$. However, women also reported that most health professionals did not attend to this need ${ }^{41}$.

This systematic review also identified some noteworthy gaps in this general line of inquiry. For example, all studies have explored parenting issues and the mother-child relationship during the diagnostic or treatments phases of $\mathrm{BC}$. Accordingly, the process of adaptation in the mother-child relationship and those involving changes in parenting and parental roles during survivorship remains unknown. During survivorship, women continue to experience some psychosocial difficulties but, at the same time, the family system has decentred from the initial shock of the diagnosis and may be able to better cope with the stress of the continuing illness ${ }^{53}$. Presently, there is insuffieient evidence regarding long-term changes in family dynamics, especially those in the mother-child relationship. These longterm effects may depend on many factors such as the developmental stage of the children or the family's pre-diagnosis functioning. Further studies are needed to explore how particular changes in mother-child interaction following $\mathrm{BC}$ and how $\mathrm{BC}$ diagnosis either facilitate or hinder family adjustment. To date, only two studies focused on this issue ${ }^{19,42}$, with both finding that the mother-child relationship tended to improve ${ }^{19,42}$. This pattern has similarly been observed in the context of other types of cancer ${ }^{9}$. However, additional studies are necessary to filuminate the factors that contribute to this improvement.

It is also noteworthy that, with one exception ${ }^{47}$ none of the reviewed studies specifically explored the father's relationship with the children. Future studies of the impacts of this relationship on the mother-child relationship are also needed, as there is indirect evidence that when the father assumes more active role in parenting, the mother's adaptation to her disease is facilitated ${ }^{18}$. Only one study ${ }^{40}$ analysed changes in terms of parental rules, but this dimension emerged spontaneously in the course of participants' interviews and was not specifically probed by the interviewer ${ }^{40}$. Therefore, future studies should additionally 
explore variability and changes in parental rules when the mother has BC. The inconsistent findings regarding mother's availability ${ }^{20,21,39}$ may be explained by mother's perceptions about what availability means. Spending more time with children does not necessarily mean that the mother is more sensitive to children's needs. The majority of reviewed studies $(91 \%)$ focused on the mother's perspectives about how BC was lived in their parenting and motherchild relationships 6 ,12,19,20,22,36-39,41-43,45,46,48-51 , and only two studies assessed the perceptions and experiences of children ${ }^{40,44}$. Thus, it is important that continuing inquiry in this domain include perceptions of children about the experience of having a mother with BC. It is possible, for instance, that in families where parents avoid talking about the mother's cancer $19,36,39,42,44,47,49$, there are noteworthy discrepancies between children's and mothers' perspectives on family dynamics.

Another important variable for further study is the severity of the disease. In this review, only $17 \%$ of the articles included women with advanced cancer. Little is known about how the severity of BC affects the mother-child relationship and in her parenting skills. Sigal and colleagues ${ }^{40}$ found differences between mothers with metastatic $\mathrm{BC}$ and those with nonmetastatic $\mathrm{BC}$ with regard to their externalizing symptoms and parenting competence. This study suggests that it is important to deepen this reality with exploratory and comparative studies.

Indeed, many other potentially important impacts of a mother's $\mathrm{BC}$ on parenting and mother-child relationship remain unexplored. For instance, we did not find any comparative studies exploring the parenting behaviours adopted by mothers who shared vs. withheld disclosure of their diagnosis from their children. Also, none of the reviewed studies explored changes in parental rules and in mother-child relationships from $\mathrm{BC}$ diagnosis into survivorship. Therefore, to better explicate the complex process of adaptation to BC for both women and their children, studies are needed that use sophisticated data analytic procedures 
for assessing the intrapersonal and interpersonal effects of mother-child emotion regulation dynamics on these participants' psychological functioning.

\section{Implications for practice}

The findings of this systematic review contribute to a better understanding of parenting and mother-child relationship in families where the mother has $\mathrm{BC}$. This enables psychologists to provide more sensitive support to BC patients, as these mothers clearly indicated a desire to talk with health professionals about their concerns regarding sharing their diagnosis with children $22,36,41,50$. For this reason, psychologists should consider exploring these concerns in a supportive manner and providing these mothers with relevant psychoeducational information regarding the needs of child according to their age and the mothers' concerns about their child's possible reactions to the diagnosis. Psychologists would also do well to inquire about recent changes in family dynamics and parenting rules. The findings further indicate that incorporating psycho-oncology as part of cancer care can not only to address psychosocial issues, but also facilitate in training health professionals and children's teachers to be more sensitive and responsive to patients' and children's needs. Additionally, these studies highlighted the importance of developing psychoeducational programs designed to provide mothers with $\mathrm{BC}$ with effective strategies for appropriately sharing their diagnosis with their children. In the majority of families, the disclosure about mother's cancer only occurs once ${ }^{37,39,43}$, and is mainly a unidirectional communication from parents to children ${ }^{39}$. However, it is important for children's adjustment that these conversations reoccurs whenever the children need them, and that they allow children to express their questions and feelings.

This study showed that the diagnosis of BC can impact the family system. For this reason, an open and effective communication of thoughts and emotions among family 
members should be encouraged. Social support dynamics, parental rules, and coping strategies should be explored and improved. For this reason, children and fathers should also be included in the psychosocial interventions offered to women with BC.

\section{Limitations}

The included studies have several limitations. For the most part, the three main themes found in this systematic review emerged essentially from interviews with women with $\mathrm{BC}$ that had children, and it is important to note that most studies only involved women with early stage BC. Thus, the majority of studies neglected the perspectives of other family members, as well as those of women with advanced cancer. Additionally, the majority of studies used qualitative methods because they sought to explore the experiences and perceptions of mothers with BC. However, given the small samples and less structured forms of inquiry typical of these methods, their findings may not be generalizable to all mothers with BC. Indeed, all of the reviewed studies used convenience samples which likely overrepresented participants who tended to be more open and comfortable for talking about their $\mathrm{BC}$ experiences, and to families who were adapting more satisfactorily to this nonnormative life event. Some inconsistencies in findings can emerge because of the lack of defining some terms, like availability. This can cause bias in interpretation of data. It is important to be aware of these limitations when interpreting these results.

Finally, while we followed PRISMA guidelines to identify eligible studies, it is possible that studies relevant to this systematic review were unintentionally excluded. For instance, some studies exploring parenting and mother-child relationship in the context of $\mathrm{BC}$ may not be included because of language constraints or because they were published in nonidentifiable resources. 


\section{Conclusions}

With this systematic review, we found that empirical research about parenting and parent-child relationship in families with mothers having BC focused essentially on three main themes. Being a mother with $\mathrm{BC}$ makes parenting a more complex experience, and because of that, these mothers need a greater informal and formal support, especially from health professionals. Although the studies about parenting and relationship between sick mothers and their children are increasing, there are still dimensions and processes that need to be further explored to improve the care provided to women with $\mathrm{BC}$ and their families.

\section{Acknowledgments}

The authors wish to thank Professor Frederick Lopez for his valuable help on commenting and editing this paper.

\section{References}

1. National Cancer Institute. SEER stat fact sheets: Female breast cancer. Surveillance, Epidemiol rend Prosults Avogr. Available at: http://seer.cancer.gov/statfacts/html/breast.html. Accessed March 24, 2016.

2. Torre EA, Bray F, Siegel RL, Ferlay J, Lortet-Tieulent J, Jemal A. Global cancer statistics, 2012. CA A Cancer J Clin. 2015;65(2):87-108. doi:10.3322/caac.21262.

3. Ferlay J, Steliarova-Foucher E, Lortet-Tieulent J, et al. Cancer incidence and mortality patterns in Europe: Estimates for 40 countries in 2012. Eur $J$ Cancer. 2013;49(6):1374-1403. doi:10.1016/j.ejca.2012.12.027.

4. Breast Cancer Organization. U.S. breast cancer statistics. 2017. Available at: http://www.breastcancer.org/symptoms/understand_bc/statistics. Accessed February 6, 2017.

5. Anders CK, Johnson R, Litton J, Phillips M, Bleyere A. Breast cancer before age 40 
years. Semin Oncol. 2009; 36(3):237-249. doi:10.1053/j.seminoncol.2009.03.001.

6. Billhult A, Segesten K. Strength of motherhood: Nonrecurrent breast cancer as experienced by mothers with dependent children. Scand J Caring Sci. 2003;17(2):122128.

7. Spiegel D, Classen C. Group therapy for cancer patients : a research-based handbook of psychosocial care. New York: Basic Books; 2000.

8. Dobkin PL, Costa D. Group psychotherapy for medical patients. Psychol Health Med. 2000; 5(1):87-96.

9. Helseth S, Ulfsæt N. Parenting experiences during cancer. J Adv Nurs. 2005;52(1):3846.

10. Pereira MG, Lopes C. A família e a doença oncológica. In: Pereira M da G, Lopes C, eds. O doente oncológico e a sua família. Lisboa: Climepsi Editores; 2002:71-99.

11. Northouse LL, Cracchiolo-Caraway A, Appel CP. Psychologic consequences of breast cancer on partner and family. Semin Oncol Nurs. 1991;7(3):216-223. doi:10.1016/0749-2081(91)90035-N.

12. Connell S, Patterson C, Newman B. Issues and concerns of young Australian women with breast cancer. Support Care Cancer. 2006;14(5):419-426. doi:10.1007/s00520005-0003-8.

13. Arès I, Lebel S, Bielajew C. The impact of motherhood on perceived stress, illness intrusiveness and fear of cancer recurrence in young breast cancer survivors over time. Psychol Health. 2014;29(6):651-670. doi:10.1080/08870446.2014.881998.

14. Rauch P, Muriel AC. The importance of parenting concerns among patients with cancer. Crit Rev Oncol Hematol. 2004;49(1):37-42. doi:10.1016/S10408428(03)00095-7.

15. Montazeri A, Vahdaninia M, Harirchi I, Ebrahimi M, Khaleghi F, Jarvandi S. Quality 
of life in patients with breast cancer before and after diagnosis: An eighteen months follow-up study. BMC Cancer. 2008;8:330-336. doi:10.1186/1471-2407-8-330.

16. Travado M. The role and challenges of psycho-oncology in improving cancer care. 2013.

17. Classen C, Diamond S, Soleman A, Fobair P, Spira J, Spiegel D. Brief supportiveexpressive group therapy for women with primary breast cancer: A treatment manual. Stanford: University School of Medicine; 1993.

18. Tavares R, Matos PM. Cancro da mama vivido na relação mãe-filhos e na parentalidade. Análise Psicológica. 2016;4(34):377-390. doi:10.14417/ap.1223.

19. Kim S, Ko YH, Jun EY. The impact of breast cancer on mother-child relationships in Korea. Psychooncology. 2012;21(6):640-646, doi:10,1002/pon.1941.

20. Fisher C, O'Connor M. "Motherhood" in the context of living with breast cancer. Cancer Nurs. 2012;35(2):157-163. do1:10.1097/NCC.0b013e31821cadde.

21. Ohlén J, Holm A-K. Transforming desolation into consolation: Being a mother with life-threatening breast cancer. Health Care Women Int. 2006;27(1):18-44. doi:10.1080/07399330500377226.

22. Stiffler D, Haase J, Hosei B, Barada B. Parenting experiences with adolescent daughters when mothers have breast cancer. Oncol Nurs Forum. 2008;35(1):113-120. doi:10.1188/08.ONF.113-120.

23. Thastum M, Watson M, Kienbacher C, et al. Prevalence and predictors of emotional and behavioural functioning of children where a parent has cancer: A multinational study. Cancer. 2009;115(17):4030-4039. doi:10.1002/cncr.24449.

24. Visser A, Huizinga GA, van der Graaf WTA, Hoekstra HJ, Hoekstra-Weebers JEHM. The impact of parental cancer on children and the family: A review of the literature. Cancer Treat Rev. 2004;30(8):683-694. doi:10.1016/j.ctrv.2004.06.001. 
25. Semple CJ, McCance T. Parents' experience of cancer who have young children: A literature review. Cancer Nurs. 2010;33(2):110-118.

26. Ernst JC, Beierlein V, Romer G, Möller B, Koch U, Bergelt C. Use and need for psychosocial support in cancer patients: A population-based sample of patients with minor children. Cancer. 2013;119(12):2333-2341. doi:10.1002/cncr.28021.

27. Huizinga GA, Visser A, van der Graaf WTA, Hoekstra HJ, Hoekstra-Weebers JEHM. The quality of communication between parents and adolescent children in the case of parental cancer. Ann Oncol. 2005;16(12):1956-1961. doi:10.1093/annonc/mdi395.

28. Harris C, Zakowski S. Comparisons of distress in adolescents of cancer patients and controls. Psychooncology. 2003;12:173-182. doi:10.1002/pon.631

29. Nelson E, Sloper P, Charlton A, While D. Children who haye a parent with cancer: A pilot study. J Cancer Educ. 1994;9(1):30-36. doi:10.1080/08858199409528262.

30. Watson M, James-Roberts S, Ashley S, et al. Factors associated with emotional and behavioural problems among school age children of breast cancer patients. $B r J$ Cancer. 2006;94(1):43-50. doi:10.1038/sj.bjc.6602887.

31. Osborn T. The psychosocial impact of parental cancer on children and adolescents: A systematic review. Psychooncology. 2007;16:101-126. doi:10.1002/pon.1113.

32. Grabiak BR, Bender CM, Puskar KR. The impact of parental cancer on the adolescent: An analysis of the literature. Psychooncology. 2007;16:127-137. doi:10.1002/pon.1083.

33. Edwards L, Watson M, James-Roberts I St., et al. Adolescent's stress responses and psychological functioning when a parent has early breast cancer. Psychooncology. 2008;17(10):1039-1047. doi:10.1002/pon.

34. Moher D, Liberati A, Tetzlaff J, Altman DG, PRISMA Group. Preferred reporting items for systematic reviews and meta-analyses: The PRISMA statement. Ann Intern 
Med. 2009;151(4):265-294. doi:10.7326/0003-4819-151-4-200908180-00135.

35. Al-Zaben F, Al-Amoudi SM, El-deek BS, Koenig HG. Impact of maternal breast cancer on school-aged children in Saudi Arabia. BioMed Cent Res Notes. 2014;7(261):1-5. doi:10.1186/1756-0500-7-261.

36. Barnes J, Kroll L, Burke O, Lee J, Jones A, Stein A. Qualitative interview study of communication between parents and children about maternal breast cancer. West $J$ Med. 2000;173(6):479-481.

37. Barnes J, Kroll L, Lee J, Burke O, Jones A, Stein A. Factors predicting communication about the diagnosis of maternal breast cancer to children. $J$ Psychosom Res. 2002;52(4):209-214. doi:10.1016/S0022-3999(02)00296-9.

38. Coyne E, Borbasi S. Holding it all together: Breast cancer and its impact on life for younger women. Contemp Nurse. 2007;23(2):157-169,

39. Shands ME, Lewis FM, Zahlis EH. Mother and child interactions about the mother's breast cancer: An interview study. Oncol Nurs Forum. 2000;27(1):77-85.

40. Sigal JJ, Perry C, Robbins JM, Gagné M, Nassif E. Maternal preoccupation and parenting as predictors of emotional and behavioral problems in children of women with breast cancer. $J$ Clin Oncol. 2003;21(6):1155-1160. doi:10.1200/JCO.2003.03.031.

41. Turner J, Clavarino A, Yates P, Hargraves M, Connors V, Hausmann S. Development of a resource for parents with advanced cancer: What do parents want? Palliat Support Caré. 2007;5(2):135-145. doi:10.1017/S1478951507070204.

42. Yoshida S, Otani H, Hirai K, et al. A qualitative study of decision-making by breast cancer patients about telling their children about their illness. Support Care Cancer. 2010;18(4):439-447. doi:10.1007/s00520-009-0682-7.

43. Asbury N, Lalayiannis L, Walshe A. How do I tell the children? Women's experiences 
of sharing information about breast cancer diagnosis and treatment. Eur J Oncol Nurs. 2014;18(6):564-570. doi:10.1016/j.ejon.2014.07.003.

44. Cho O-H, Yoo Y-S, Hwang K-H. Comparison of parent-child communication patterns and parental role satisfaction among mothers with and without breast cancer. Appl Nurs Res. 2015;28(2):163-168. doi:10.1016/j.apnr.2014.09.005.

45. Elmberger E, Bolund C, Lützén K. Transforming the exhausting to energizing process of being a good parent in the face of cancer. Health Care Women Int. 2000;21(6):485499.

46. Mazzotti E, Serranò F, Sebastiani C, Marchetti P. Mother-child relationship as perceived by breast cancer women. Psychology. 2012;3(12):1027-1034.

47. Walsh SR, Manuel JC, Avis NE. The impact of breast cancer on younger women's relationships with their partner and children. Famlies, Syst Heal. 2005;23(1):80-93. doi:10.1037/1091-7527.23.1.80.

48. Vickberg SMJ. Locating breast cancer in the context of women's lives. J Psychosoc Oncol. 2003;21(2):69-88. doi:10.1300/J077v21n02.

49. Mackenzie CR. "It is hard for mums to put themselves first": How mothers diagnosed with breast eancer manage the sociological boundaries between paid work, family and caring for the self. Soc Sci Med. 2014;117:96-106. doi:10.1016/j.socscimed.2014.07.043.

50. Stinesen-Kollberg K, Thorsteinsdottir T, Wilderäng U, Steineck G. Worry about one’s own children, psychological well-being, and interest in psychosocial intervention. Psychooncology. 2013;22(9):2117-2123. doi:10.1002/pon.3266.

51. Stinesen-Kollberg K, Wilderäng U, Möller A, Steineck G. Worrying about one's children after breast cancer diagnosis: Desired timing of psychosocial intervention. Support Care Cancer. 2014;22(11):2987-2995. doi:10.1007/s00520-014-2307-z. 
52. Vaismoradi $\mathrm{M}$, Turunen $\mathrm{H}$, Bondas $\mathrm{T}$. Content analysis and thematic analysis: Implications for conducting a qualitative descriptive study. Nurs Heal Sci. 2013;15(3):398-405. doi:10.1111/nhs.12048.

53. McCubbin HI, Patterson JM. The family stress process: The double ABCX model of adjustment and adaptation. Marriage Fam Rev. 1983;6(1-2):7-37. doi:10.1300/J002v06n01. 
Table 1. Results of studies organized by themes and their dimensions

\begin{tabular}{|c|c|}
\hline Themes & Dimensions \\
\hline \multirow{5}{*}{ Priorities and concerns of patients } & Changes in priorities in social roles \\
\hline & Negative feelings when health comes in first place \\
\hline & Decisions about treatments depending on the priorities \\
\hline & Concerns with the children \\
\hline & Need to talk to professionals about children \\
\hline \multirow{2}{*}{$\begin{array}{l}\text { Decision-making process about sharing the } \\
\text { diagnosis with children }\end{array}$} & Reasons for decision \\
\hline & Talk about mother's diagnosis \\
\hline \multirow{8}{*}{$\begin{array}{l}\text { Mother-child relationship and parenting after } \\
\text { mother's diagnosis }\end{array}$} & Beliefs and feelings about parental abilities after BC \\
\hline & Parental strategies \\
\hline & Parental rules \\
\hline & Parental aims \\
\hline & Availability of mothers \\
\hline & Division of parental task \\
\hline & Mother-child relationship \\
\hline & Motherhood as a protector factor for the patients \\
\hline
\end{tabular}


Table 2. Themes in the literature about parenting, and mother-child relationship in families that mother has cancer

\begin{tabular}{|c|c|c|c|}
\hline Authors [country] & $\begin{array}{l}\text { Priorities and } \\
\text { concerns of patients }\end{array}$ & $\begin{array}{c}\text { Decision-making } \\
\text { process about sharing } \\
\text { the diagnosis with } \\
\text { children }\end{array}$ & $\begin{array}{l}\text { Mother-child } \\
\text { relationship and } \\
\text { parenting after } \\
\text { mother's diagnosis }\end{array}$ \\
\hline $\begin{array}{l}\text { Al-Zaben et al., 2014 } \\
\text { [Saudi Arabia] }\end{array}$ & & 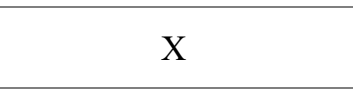 & \\
\hline $\begin{array}{l}\text { Asbury el al., 2014 } \\
\text { [England] }\end{array}$ & $X$ & $\mathrm{X}$ & \\
\hline $\begin{array}{l}\text { Barnes et al., 2000 } \\
\text { [England] }\end{array}$ & $X$ & $X$ & \\
\hline $\begin{array}{c}\text { Barnes et al., 2002 } \\
\text { [England] }\end{array}$ & $\mathrm{X}$ & $X$ & $x$ \\
\hline $\begin{array}{l}\text { Billhult and Segesten, } 2003^{6} \\
\text { [Sweden] }\end{array}$ & $X$ & $X$ & \\
\hline $\begin{array}{c}\text { Cho et al., } 2015^{44} \\
\text { [South Korea] }\end{array}$ & & & $X$ \\
\hline $\begin{array}{c}\text { Connell et al., 2006 } \\
\text { [Australia] }\end{array}$ & $\mathrm{X}$ & & $\mathrm{X}$ \\
\hline $\begin{array}{c}\text { Coyne and Borbasi, } 2007^{38} \\
\text { [Australia] }\end{array}$ & $X$ & & $X$ \\
\hline $\begin{array}{c}\text { Elmberger et al., 2000 } \\
\text { [Sweden] }\end{array}$ & X & $X$ & $\mathrm{X}$ \\
\hline $\begin{array}{l}\text { Fisher and O'Connor, } 2012^{20} \\
\text { [Australia] }\end{array}$ & & & $X$ \\
\hline $\begin{array}{c}\text { Kim et al., 2012 } \\
\text { [South Korea] }\end{array}$ & & X & $\mathrm{X}$ \\
\hline $\begin{array}{l}\text { Mackenzie, } 2014^{49} \\
\text { [Australia] }\end{array}$ & & X & X \\
\hline $\begin{array}{c}\text { Mazzotti et al., } 2012^{46} \\
\text { [Italy] }\end{array}$ & X & $\mathrm{X}$ & X \\
\hline $\begin{array}{c}\text { Ohlén and Holm, } 2006 \\
\text { [Sweden] }\end{array}$ & $\mathrm{X}$ & & $\mathrm{X}$ \\
\hline $\begin{array}{c}\text { Shands et al., } 200 \\
\text { [USA] }\end{array}$ & & $\mathrm{X}$ & $\mathrm{X}$ \\
\hline $\begin{array}{l}\text { Sigal et al. } 2003^{40} \\
\text { [Canada] }\end{array}$ & & & $\mathrm{X}$ \\
\hline $\begin{array}{c}\text { Stiffler et al., } 2008^{22} \\
\text { [USA] }\end{array}$ & $X$ & & $X$ \\
\hline $\begin{array}{c}\text { Stinesen-Kollbeng et al., } 2013^{50} \\
\text { [Sweden] }\end{array}$ & $\mathrm{X}$ & & \\
\hline $\begin{array}{l}\text { Stinesen-Kollbeng et al., } 2014^{51} \\
\text { [Sweden] }\end{array}$ & $X$ & & \\
\hline $\begin{array}{c}\text { Turner et al., 2007 } \\
\text { [Australia] }\end{array}$ & $\mathrm{X}$ & $\mathrm{X}$ & $\mathrm{X}$ \\
\hline $\begin{array}{c}\text { Vickberg, } 2003^{48} \\
\text { [USA] }\end{array}$ & & & X \\
\hline $\begin{array}{c}\text { Walsh et al., } 2005^{47} \\
\text { [USA] }\end{array}$ & $\mathrm{X}$ & & $\mathrm{X}$ \\
\hline $\begin{array}{l}\text { Yoshida et al., } 2010^{42} \\
\text { [Japan] }\end{array}$ & & X & X \\
\hline
\end{tabular}

